University of Nebraska - Lincoln

DigitalCommons@University of Nebraska - Lincoln

Faculty Publications from the Harold W. Manter Laboratory of Parasitology

6-1999

\title{
Macroevolutionary Patterns of Male Reproductive Investment in a Clade of Parasitic Hermaphrodites
}

\author{
David Zamparo \\ University of Toronto \\ Deborah A. McLennan \\ University of Toronto \\ Daniel R. Brooks \\ University of Toronto,dnlbrooks@gmail.com
}

Follow this and additional works at: https://digitalcommons.unl.edu/parasitologyfacpubs

Part of the Parasitology Commons

Zamparo, David; McLennan, Deborah A.; and Brooks, Daniel R., "Macroevolutionary Patterns of Male Reproductive Investment in a Clade of Parasitic Hermaphrodites" (1999). Faculty Publications from the Harold W. Manter Laboratory of Parasitology. 203.

https://digitalcommons.unl.edu/parasitologyfacpubs/203

This Article is brought to you for free and open access by the Parasitology, Harold W. Manter Laboratory of at DigitalCommons@University of Nebraska - Lincoln. It has been accepted for inclusion in Faculty Publications from the Harold W. Manter Laboratory of Parasitology by an authorized administrator of DigitalCommons@University of Nebraska - Lincoln. 


\title{
MACROEVOLUTIONARY PATTERNS OF MALE REPRODUCTIVE INVESTMENT IN A CLADE OF PARASITIC HERMAPHRODITES
}

\author{
David Zamparo, Deborah A. McLennan*, and Daniel R. Brooks \\ Centre for Comparative Biology and Biodiversity, Department of Zoology, University of Toronto, Toronto, Ontario, Canada M5S 3 G5
}

\begin{abstract}
The Eucestoda is particularly relevant for questions concerning reproductive investment in male gametes because no other parasitic group displays such diversity in testis size and number within and among species. This diversity has long been used as a valuable taxonomic character, but few researchers have ever investigated its evolutionary significance. In this paper we investigate the evolution of testis number and size within Rhinebothroides (Platyhelminthes: Eucestoda). Our comparative, phylogenetic analysis revealed that overall allocation to male functions, as measured by relative testicular area, does not change within the clade, even though the packaging of that investment in numerous testes is highly variable within, and diverse among, members of the group.
\end{abstract}

In 1871, Darwin wrote "We are naturally led to enquire why the male in so many and such widely distinct classes has been rendered more eager than the female, so that he searches for her and plays the more active part in courtship" (p. 273). Less than one page later, he answered his own query, proposing that "the ova, even if being detached before being fertilized and not requiring subsequent nourishment or protection, would be, from their relative size, less easily transported than the male element" (p. 274). Of Darwin's many fundamental insights into the nature of biological evolution, the recognition that the size disparity between eggs and sperm lay at the heart of intersexual conflict over mating, was surely one of his most important contributions. It formed the immediate foundation for his theory of sexual selection. It took 77 more years however, before Bateman (1948) expanded and refined Darwin's insight to delineate one of the principles that lies at the heart of life-history theory: female reproductive success is limited by the availability of resources to make eggs, whereas male reproductive success is limited by the availability of eggs. All other things being equal, a male's reproductive success is based upon his ability to acquire fertilizations, rather than in his ability to produce gametes, because all males can produce enough sperm to fertilize many eggs (females). If all other things are not equal, e.g., females mate with more than 1 male or a large excess of sperm is required to ensure fertilization, then male reproductive success should be more intimately tied to sperm production (reviewed in Møller and Briskie, 1995).

Although the predictions of sexual conflict theory have generally been investigated for dioecious species, there is no reason why the theory should not apply to hermaphroditic species as well (Bateman, 1948; Charnov, 1979). Models of resource allocation in simultaneous hermaphrodites predict that selection should favor shunting resources from male to female functions if mating occurs between sedentary partners, especially if those partners are capable of reducing male gamete wastage via, for example, internal fertilization (Altenberg, 1934; Tomlinson, 1966; Maynard Smith, 1972; Charnov et al., 1976; Charnov, 1996). If male gametes are so plentiful that they overwhelm available eggs among females in close proximity, there will be competition for fertilizations among the sperm from a single male. This interaction produces a saturating or asymptoting fit-

Received 20 July 1998; revised 13 November 1998; accepted 13 November 1998.

* Corresponding author. ness gain curve. Simultaneous hermaphrodites should allocate less than half of their resources to male functions once male reproductive success reaches the saturation point on that curve because, from that point onward, further investment in male function produces a rapidly dwindling fitness return (Charnov et al., 1976; Charnov, 1979, 1980, 1982; reviewed in Sella, 1992). The focus of selection, however, could shift toward male allocation if competition among sperm from different males exists in the population. For example, McCartney (1997) reported that fertilization success in the free-spawning, colonial bryozoan, Celleporella hyalina, increased linearly with number of male zooids (a measure of colonial investment in male gametes). He suggested that sperm competition was an important component of this bryozoan's breeding system because males could not monopolize access to females.

Empirical data about the allocation of resources to male functions in simultaneous hermaphrodites are rare and tend to be focused upon either plants or free-living animals (for a review see McCartney, 1997). To date, no one has investigated the question for parasites, the animal groups that traditionally have been thought to invest an unusually large amount of their energy budget in reproduction (e.g., Price, 1974, 1980; Stunkard, 1975; Kennedy, 1976). The Eucestoda is particularly relevant for questions concerning reproductive investment in male gametes because no other parasitic group displays such diversity in testis size and number within and among species. This diversity has long been used as a valuable taxonomic character, but few researchers have ever investigated its evolutionary significance. Does the number of testes reflect overall male resource allocation and, if so, why does testis number vary so markedly among closely related species?

Rhinebothroides Mayes, Brooks, and Thorson, 1981 is a clade of 7 described species of tetraphyllidean eucestodes inhabiting the spiral valves of South American freshwater stingrays. Interspecific variability in testis number in this group ranges from a high of 99 testes/proglottid in Rhinebothroides scorzai (Lopez-Neyra and Diaz-Ungria, 1958) Mayes, Brooks, and Thorson, 1981 to a low of 19 in Rhinebothroides mclennanae Brooks and Amato, 1992, with mean values ranging from 78 to 80 testes/proglottid in $R$. scorzai and Rhinebothroides circularisi Mayes, Brooks, and Thorson, 1981 to 31 in $R$. mclennanae. Based on the theory discussed above, there are 2 possible explanations for this difference: (1) the amount of male reproductive investment differs among the species and is a reflection of changes in life history parameters like population 
density and the intensity of sperm competition; or, (2) the amount of male reproductive investment is constant, and the variability in testes number reflects different ways of packaging the same resource (male gametes). In the present paper, we present results of a comparative phylogenetic analysis of male reproductive investment within Rhinebothroides.

\section{MATERIALS AND METHODS}

\section{Phylogenetic tree}

The strength of a comparative phylogenetic analysis is dependent, in part, on the robustness of the phylogenetic tree used to trace the macroevolutionary patterns of character origin and diversification (Brooks and McLennan, 1991, 1993). Phylogenetic systematic analysis of 13 transformation series derived from a comparative morphological study produced a single most parsimonious tree for Rhinebothroides with a consistency index of 0.77 (Zamparo et al., 1999). The high consistency index indicates that the resultant tree represents a good fit to the available data.

\section{Specimens}

Specimens of $R$. circularisi (HWML no. 21020; $\mathrm{N}=15$ ), Rhinebothroides glandularis Brooks, Mayes, and Thorson, 1981 (HWML no. 21007; N = 19), Rhinebothroides venezuelensis Brooks, Mayes, and Thorson, 1981 (HWML no. 21005-6, 21024-25; $\mathrm{N}=37$ ), and $R$. scorzai (HWML no. 21014-5; $\mathrm{N}=7$ ) were borrowed from the Harold W. Manter Laboratory, University of Nebraska. Specimens of $R$. mclennanae $(\mathrm{N}=22)$ were collected by $\mathrm{F}$. Marques in 1995 from Puerto Reconquista, Santa Fé, Argentina $\left(59^{\circ} 42^{\prime} \mathrm{W}, 29^{\circ} 29^{\prime} \mathrm{S}\right)$. There were not enough mature specimens of Rhinebothroides moralarai (Brooks and Thorson, 1976) Mayes, Brooks, and Thorson, 1981 to be included in the analysis, nor were we able to get specimens of Rhinebothroides freitasi (Rego, 1979) Brooks, Mayes, and Thorson 1981. The phylogenetic analysis of Zamparo et al. (1999) also revealed that Pararhinebothroides hobergi Zamparo, Brooks, and Barriga, 1999 was the putative sister species of Rhinebothroides. We therefore used $P$. hobergi $(\mathrm{N}=23)$ as the outgroup to polarize character transformation series in this study.

\section{Measurements}

Measurements of male reproductive output include ejaculate production, spermatophore size, testes size, and sperm reserves. In the present paper, we will use testis area as our measure of reproductive allocation based upon the assumption that size is a reliable indicator of gamete production. This assumption has been widely used by other authors to estimate reproductive output when living specimens are not available for study (see e.g., Møller and Briskie, 1995). When a testis is examined under a compound microscope, it appears to be spherical. We therefore measured the diameter of each testis, then calculated the area based upon the assumption that all testes are round in shape. Measuring testis number and area is complicated in eucestodes such as Rhinebothroides because testis development follows a gradual progression from immature near the anterior end of the worm through gradual maturation, to degeneration and loss in the gravid proglottids. To standardize data collection, we therefore used only the posteriormost nongravid (mature) proglottid from each specimen. Individual proglottids were drawn using a drawing tube, and the diameter of each testis in the proglottid was measured from the drawing using Vernier dial calipers. The area for each testis in a proglottid was summed to give the total or absolute testicular area/proglottid. In order to determine whether interspecific differences in absolute testicular area might simply reflect interspecific differences in proglottid size, we measured the proglottid area using a Houston Instrument HIPAD digitizer with a Bausch \& Lomb cross-hair cursor, and the "Coral" software program. We then calculated the ratio of absolute testicular area/proglottid area to give relative testicular area.

\section{Statistical and character analysis}

Measurements for the ingroup and the outgroup were compared using ANOVA tests. In cases where the ANOVA detected a significant difference, Tukey's analyses were used to highlight the unusual taxa. Be- cause Tukey's analysis operates at $P>0.05$, we will not append the $P$ value to significant differences highlighted by the test in the Results section. Character evolution was determined by using the results of the statistical analyses to determine which values were significantly different from one another for a particular measurement, then assigning character polarities based upon outgroup comparisons. For example, if the statistical tests revealed no difference between the mean value for a trait in the outgroup and the mean value for that trait in some members of the ingroup, then that value was considered the plesiomorphic state (character state $=0$ ). If, on the other hand, the mean value for a trait differed for a given species when compared to the outgroup, or to other members of the ingroup, then that value was considered apomorphic (character state $=1$ ). These a priori hypotheses of character transformation, based upon statistical analysis and outgroup comparison, were then optimized onto the phylogenetic tree for Rhinebothroides following the procedures outlined by Maddison et al. (1984).

\section{RESULTS}

ANOVA tests revealed a significant difference among the 6 species in number of testes $(F=68.56 ; P>0.0001)$, individual testis size $(F=3.39 ; P>0.007)$, both absolute $(F=5.50 ; P$ $>0.0001)$ and relative $(F=55.74 ; P>0.0001)$ testicular area, and proglottid area $(F=10.22 ; P>0.0001)$. Tukeys analysis revealed no difference in total testis area between any members of the ingroup and the outgroup, or among members of the ingroup except for $R$. mclennanae, which showed a significant decrease in absolute testis area compared with its sister group, $R$. glandularis. With the exception of $R$. scorzai, all Rhinebothroides species have significantly larger proglottids than the outgroup. As reported previously, testis number is extremely variable in this genus; $R$. mclennanae has significantly fewer testes compared to its sister group, $R$. glandularis, and the outgroup, whereas $R$. scorzai has significantly more, and smaller, testes than all other members of the ingroup.

Optimizing these results on the phylogenetic tree for Rhinebothroides (Fig. 1) indicated that (1) absolute testis area is conserved (plesiomorphic) in all members of the ingroup, although $R$. mclennanae shows an apomorphic decrease in total testis area compared to its sister group $R$. glandularis; and (2) an increase in proglottid size is a synapomorphy for Rhinebothroides, except for $R$. scorzai, which shows a reversal to the plesiomorphic (outgroup) proglottid size, an apomorphic increase in testis number, and an apomorphic decrease in individual testis size.

\section{DISCUSSION}

Researchers have been fascinated with the relationship between male testis size, sperm output, and siring efficiency for decades. That interest has spawned a plethora of models that can loosely be grouped into 2 categories, i.e., linear and asymptoting. In a linear system, sperm output by a focal male translates directly into male reproductive success, so fitness returns on reproductive allocation can, theoretically at least, increase without bound. In an asymptoting system, individual male reproductive success has an upper limit determined by the number of available female gametes. Increasing sperm output by a focal male is thus eventually associated with decelerating fitness returns, as the amount of sperm produced swamps the eggs available for fertilization. Sex allocation theory predicts that the asymptotic relationship between fitness and gamete production is fundamental to maintaining the evolutionary stability of simultaneous hermaphroditism (reviewed in McCartney, 1997). All 


$\begin{array}{lllllllll}\# \text { testes } & 37.6 & ? & 49.8 & 58.8 & \mathbf{7 2 . 4} & ? & 43.1 & 30.1^{*} \\ \text { Testis area } & 2.1 & ? & 2.0 & 1.4 & \mathbf{1 . 3} & ? & 2.1 & 1.8 \\ \text { Total testis area } & 78.9 & ? & 102.2 & 84.7 & 95.9 & ? & 90.2 & 54.0^{*} \\ \text { Proglottid area } & 207.7 & ? & 617.0 & 580.6 & \mathbf{2 8 0 . 5} & ? & 509.2 & 433.9 \\ \text { Ratio } & .38 & & .18 & .15 & .34 & ? & .19 & .12\end{array}$

OUTGROUP moralarai venezuelensis circularisi scorzai freitasi glandularis mclennanae

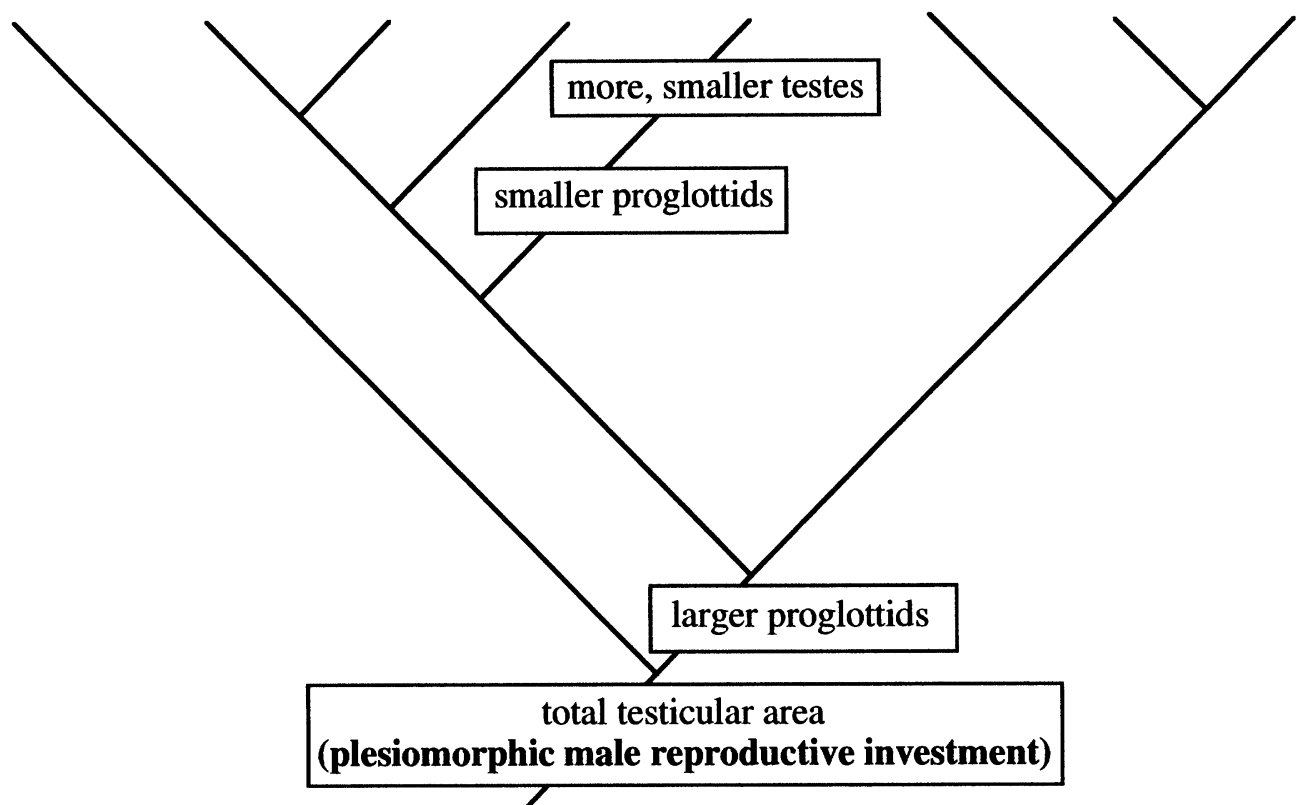

FIGURE 1. Mean values for characters mapped above, and optimized onto, the phylogenetic tree for Rhinebothroides. Measurements for testis area and proglottid area are in $\mathrm{mm}^{2}$. Bold face type indicates that the value is significantly different $(P>0.05)$ from the outgroup. ${ }^{*}$ Indicates that the value is significantly different from the sister group but not different from the outgroup.

of the empirical evidence for linear and asymptoting systems has been collected by manipulating various ecological parameters within a given free-living species. This is the first study to address the question of variability in male reproductive allocation for parasites, animals that traditionally have been thought to invest an unusually large amount of their energy budget in reproduction. It is also the first study to ask the question within a macroevolutionary framework. That is, are intraspecific differences in male reproductive allotment manifested on a macroevolutionary, or interspecific, time scale?

One of the most striking things about Rhinebothroides is the large range in testis number among its members; in fact, number of testes is a useful character for diagnosing particular species, even though there is substantial homoplasy associated with it phylogenetically (Zamparo et al., 1999). There are 2 possible explanations for such interspecific variability; either the allocation to male function has changed within the group, in which case the macroevolutionary patterns may reflect 1 of the underlying microevolutionary dynamics discussed above, or male reproductive investment has remained constant and has simply been packaged differently over time. The second explanation can be thought of as macroevolutionary wandering or drift through reproductive space in which all states represent inter- specific equivalents. Our analysis provides support for the second explanation. All Rhinebothroides species display the plesiomorphic absolute testis area (plesiomorphic male reproductive output: Fig. 1). That output is simply packaged differently within the genus; it comes in either fewer larger, or more smaller packets. In other words, the obvious interspecific variability in testis number is not correlated with interspecific variability in male reproductive output. It is the relatively unconstrained macroevolutionary wandering within the plesiomorphic testis area that explains why testis number can be a useful diagnostic character and yet exhibit substantial homoplasy.

This wandering has produced an interesting result; $R$. mclennanae shows a significant decrease in male reproductive output compared to its sister species, $R$. glandularis, due primarily to a decrease in the number of testes, although neither species differs significantly from the outgroup. This result may be purely coincidental; $R$. glandularis shows a slight, but not significant, increase over the outgroup condition whereas $R$. mclennanae shows a slight, but again not significant, decrease. Looking at the values for total testis area mapped on Figure 1, it is tempting to propose that we have caught evolution in transition; that, although the results are not significant at the moment, we may be witnessing an evolutionary decrease in male reproduc- 
tive investment in $R$. mclennanae. As mentioned previously, in simultaneous, sedentary hermaphrodites, diminishing fitness returns are expected if male gametes are so plentiful that they overwhelm available eggs in surrounding females, leading to competition for fertilizations among the sperm from 1 male. This interaction produces a saturating or asymptoting fitness gain curve (Charnov et al., 1976; Charnov, 1979, 1982). If Rhinebothroides species fall at the high end of the asymptote, it is possible that most members of this clade actually produce more sperm than they need to fertilize available eggs. Any mutation that decreases sperm output would, therefore, be at a selective advantage once it appeared because overproduction is, from an evolutionary perspective, a waste of resources. On the other hand, the decrease in testis area could reflect a change in the population biology of this species. Charnov (1980; see also Heath, 1977) predicted that the proportion of reproductive resources allocated to male function should be tied to the size of the mating group. According to his model, as the mating group gets smaller, resource allocation to male function should decrease. To date, there are no observations of population structure for Rhinebothroides species. It would be interesting to determine whether the average group size (mean intensity) of $R$. mclennanae was significantly less than that of other Rhinebothroides species.

The observation that male reproductive output has not changed significantly across the macroevolutionary history of Rhinebothroides tells us very little about the microevolutionary processes that are responsible for maintaining that output. It is possible that male gamete production has reached its upper limit in this group, or that the plesiomorphic male output represents the optimal balance between male and female function given the mating group size (Heath, 1977; Charnov, 1980). The conservative nature of reproductive output implies that there are no differences in life-history parameters such as the intensity of sperm competition, availability of mates (mating group size), and quantity of sperm needed for effective insemination among the members of this relatively small genus. Without comparable data from closely related groups, however, we cannot judge whether the total testicular area that is plesiomorphic to this clade is unusual in relation to other members of the Phyllobothriidae. Before we can begin to understand the transition from macroevolutionary patterns to microevolutionary processes, we need to collect information about mating group size, the relationship between male reproductive investment and fitness, etc., for all members of Rhinebothroides, and to expand the taxonomic scope of this study in order to pinpoint the ancestor in which the allocation to male reproductive output changed (Brooks and McLennan, 1991).

Our analysis also indicates that Rhinebothroides as a group may display an apomorphic increase in proglottid area, with a reversal to the plesiomorphic proglottid size in $R$. scorzai. This hypothesis is tentative, however, pending data from $R$. freitasi, because it is equally parsimonious to hypothesize that proglottid area increased independently in the ancestor of $R$. circularisi + $R$. venezuelensis $+R$. moralarai and in the ancestor of $R$. glandularis $+R$. mclennanae. If $R$. freitasi has significantly larger proglottids than the outgroup, then the optimization remains ambiguous; one possibility is that the proglottids of $R$. scorzai got smaller? If, on the other hand, $R$. freitasi shows the plesiomorphic proglottid size, then the second optimization dis- cussed above is supported. The change in proglottid size was not accompanied by a change in male reproductive output. At first glance, this observation would appear to contradict predictions that closely related organisms will shunt relatively constant energy allocation between somatic growth and reproduction (Koslowski, 1992). There are 2 possible explanations for this seemingly anomalous situation. First, there is a direct relationship between proglottid size and the surface area available to absorb nutrients from the host's intestine. The increase in proglottid size may, therefore, have been accompanied by an increase in available energy, allowing the system to maintain the plesiomorphic male reproductive output even in the face of an increase in the energy allotted to somatic tissue development. Second, Darwin (1859) proposed that large adult size will be favored if it is linked with higher fecundity. This hypothesis has been confirmed for a number of free-living invertebrate species as well as members of the parasitic platyhelminths (see e.g., Stearns, 1992). Interestingly, Rhinebothroides shows an apomorphic change in a female reproductive character that may be correlated with this size change, i.e., the appearance of a highly branched uterus (a trait also appearing convergently in proteocephalideans and cyclophyllideans such as catenotaeniids and taeniids). If this change in uterine morphology is correlated with increased female reproductive investment (more eggs can be stored and begin to develop in the relative protection of the proglottid), then the increase in proglottid size could have been favored because it was indirectly linked to increased female fecundity.

In summary, this analysis within 1 genus of parasitic simultaneous hermaphrodites has revealed that overall allocation to male functions does not change within the clade, even though the packaging of that investment is highly variable within, and diverse among, members of the group. One of the powers of the comparative phylogenetic approach is that it allows us to highlight areas for future research (Brooks and McLennan, 1991, 1993; McLennan, 1996). In this case, our analysis has raised a number of additional questions about the factors influencing the evolution of proglottid size and allocation to female function. Answers to these questions must consider further details regarding the biology of the group, including population structure, mating group size, embryo development, adult and juvenile mortality, and the effects of selfing versus outcrossing on individual fitness. Life-history theory has produced a number of models delineating the potential effect of such biological parameters on the allocation of resources to male and female function in simultaneous hermaphrodites. Echoing the sentiments of Mayr (1957), we believe that parasitologists are sitting on a gold mine of information that could be used to examine and possibly modify these models in the future.

\section{ACKNOWLEDGMENTS}

Funds for this study were provided by operating grants from the Natural Sciences and Engineering Research Council of Canada to D.A.M. and D.R.B. We are deeply indebted to F. Marques for providing specimens of $R$. mclennanae, to $\mathrm{S}$. Sterner (Collections Manager, Harold W. Manter Laboratory, University of Nebraska State Museum) for providing specimens of the remaining species so promptly, to $\mathbf{M}$. Telford for lending us his digitizer and Coral software program, to J. Stone for 
teaching us, with great patience, how to use it, and to 3 anonymous reviewers whose comments greatly improved this paper.

\section{LITERATURE CITED}

AltenBERG, E. 1934. A theory of hermaphroditism. American Naturalist 68: $88-91$.

Bateman, A. J. 1948. Intra-sexual selection in Drosophila. Heredity 2: 349-368.

Brooks, D. R., AND J. F. R. Amato. 1992. Cestode parasites in Potamotrygon motoro (Muller and Henle) (Chondrichthyes: Potamotrygonidae) from southwestern Brazil, including Rhinebothroides mclennanae sp. n. (Tetraphyllidea: Phyllobothriidae) and a revised host-parasite checklist for helminths inhabiting Neotropical freshwater stingrays. Journal of Parasitology 78: 393-398.

- M. A. MAYes, AND T. B. ThORSON. 1981. Systematic review of cestodes infecting freshwater stingrays (Chondrichthyes: Potamotrygonidae) including four new species from Venezuela. Proceedings of the Helminthological Society of Washington 48: 43-64.

- AND D. A. MCLENNAN. 1991. Phylogeny, ecology, and behavior. University of Chicago Press, Chicago, Illinois, 434 p. , AND - 1993. Parascript: Parasites and the language of evolution. Smithsonian Institution Press, Washington, D.C., 429 p.

Charnov, E. L. 1979. Simultaneous hermaphroditism and sexual selection. Proceedings of the National Academy of Sciences USA 76: 2480-2484.

1980. Sex allocation and local mate competition in barnacles. Marine Biology Letters 1: 269-272.

. 1982. The theory of sex allocation. Princeton University Press, Princeton, New Jersey, 355 p.

. 1996. Sperm competition and sex allocation in simultaneous hermaphrodites. Evolutionary Ecology 10: 457-462.

, J. MAYNARD SMith, AND J. J. Bull. 1976. Why be a hermaphrodite? Nature 263: 125-126.

DARWIN, C. 1859. The origin of species. J. Murray, London, U.K., $432 \mathrm{p}$. . 1871. The descent of man, and selection in relation to sex. J. Murray, London, U.K., 475 p.

Heath, D. J. 1977. Simultaneous hermaphroditism; cost and benefit. Journal of Theoretical Biology 64: 363-373.
KENNEDY, C. R. 1976. Reproduction and dispersal. In Ecological aspects of parasitology. C. R. Kennedy (ed.). Academic Press, London, U.K., p. 27-80.

KosLOWSKI, J. 1992. Optimal allocation of resources to growth and reproduction; Implications for age and size at maturity. Trends in Ecology and Evolution 7: 15-19.

Maddison, W. P., M. J. Donoghue, and D. R. Maddison. 1984. Outgroup analysis and parsimony. Systematic Zoology 33: 83-103.

MAYNARD SMITH, J. 1972. On evolution. Edinburgh University Press, Edinburgh, U.K., 125 p.

MAYR, E. 1957. Evolutionary aspects of host specificity among parasites of vertebrates. In Premier symposium sur la spécificité parasitaire des parasites des vertébrés, J. G. Baer (ed.). Paul Attinger, Neuchâtel, France, p. 7-14.

MCCARTNEY, M. A. 1997. Sex allocation and male fitness gain in a colonial, hermaphroditic marine invertebrate. Evolution 51: 127 140.

MCLENNAN, D. A. 1996. Integrating phylogenetic and experimental analyses: The evolution of male and female nuptial coloration in the Gasterosteidae. Systematic Biology 45: 261-277.

MøLlER, A. P., AND J. V. BRISKIE. 1995. Extra-pair paternity, sperm competition and the evolution of testis size in birds. Behavioural Ecology and Sociobiology 36: 357-365.

PRICE, P. W. 1974. Strategies for egg production. Evolution 28: 76-84. . 1980. Evolutionary biology of parasites. Princeton University Press, Princeton, New Jersey, $237 \mathrm{p}$.

SELLA, G. 1992. Sex allocation in simultaneous and protandrous hermaphroditic animals. In Sex origin and evolution, R. Dallai (ed.). Selected symposia and monographs U. Z. I., 6 Mucchi, Modena, Italy, p. 369-378.

STEARNS, S. C. 1992. The evolution of life histories. Oxford University Press, New York, New York, 249 p.

STUNKARD, H. W. 1975. Life-histories and systematics of parasitic flatworms. Systematic Zoology 24: 378-385.

Tomlinson, J. 1966. The advantages of hermaphroditism and parthenogenesis. Journal of Theoretical Biology 11: 54-58.

Zamparo, D., D. R. BRooks, AND R. BARRIGA. 1999. Pararhinebothroides hobergi $\mathrm{n}$. gen. n. sp. (Eucestoda: Tetraphyllidea) in Urobatis tumbesensis (Chondrichthyes: Rajiformes) from coastal Ecuador. Journal of Parasitology 85: 534-539. 